THE EDUCATIONAL RESEARCH-PRACTICE INTERFACE REVISITED:

\title{
A SCRIPTING PERSPECTIVE
}

This is a post-print of an article submitted for consideration in the Educational Research and Evaluation (C) 2007 Taylor \& Francis.

Personal use of this manuscript is permitted. Permission from Taylor \& Francis must be obtained for any other commercial purpose.

This article may not exactly replicate the published version, due to editorial changes and/or formatting and corrections during the final stage of publication. Interested readers are advised to consult the published version which can be found at:

http://www.tandfonline.com/doi/abs/10.1080/13803610701626150

doi: $\{10.1080 / 13803610701626150\}$

Please refer this manuscript as:

Bauer, K., \& Fischer, F. (2007). The educational research-practice interface revisted: A scripting perspective. Educational Research and Evaluation, 13(3), 221-236. 
Running head: RESEARCH-PRACTICE INTERFACE

The educational research-practice interface revisited: A scripting perspective Korinna Bauer, Helmholtz Association of German Research Centres ${ }^{1}$ Frank Fischer, University of Munich

\footnotetext{
${ }^{1}$ The main work on this article was done while working at the Knowledge Media Research Center,
} Tuebingen. 


\begin{abstract}
The question of how the realms of research and practice might successfully relate to one another is a persisting one, and especially so in education. The article takes a fresh look at this issue by using the terminology of collaboration scripts to reflect upon various forms of this relationship. Under this perspective, several approaches towards bridging the research/ practice gap are being described with regard to the type and closeness of interaction between the two realms. As different focuses and blind spots become discernible, the issue is raised concerning which 'script' might be appropriate depending upon the starting conditions of research interacting with practice.
\end{abstract}

Key words

Research-Practice Interface, collaboration script, research strategy, use-inspired basic research 
The educational research-practice interface revisited: A scripting perspective

What will be discussed in this article is a problem almost any discipline has to face: The question how research and practice can successfully relate to one another. However, it seems that this issue is more vexing for some fields of research (and practice, respectively) than for others. Engineering research, for instance, has established firm pathways to practical development and application, formalizing even the accompanying juridical aspects. Medicine is another prime example for an institutionalized linkage between research and practice; a linkage which is getting even closer now due to the recent development of 'translational centres' uniting basic and clinical research under one roof.

When it gets to education, however, the account is ostensibly less splendid. Of course, reflections on the relation of research and practice have some tradition in education, but their history seems too marked by rapid successions of euphoria and disappointments (Kennedy, 1997) as to provide a firm, systematically refined basis on which one could build. Established exchange structures between the two realms are lacking: as Burkhardt and Schoenfeld (2003, p. 7) put it, “it's (almost) nobody's job to turn insight into impact”. Unsurprisingly, research and practice largely seem to be separate spheres. Taking the history of education in Germany during the last fifty years for instance, what has triggered the great educational reforms seems to have been anything from zeitgeist to copy-cat solutions borrowed from other realms, but only rarely something that educational research would have unveiled or 'invented'.

This apparently independent development of research on the one hand and practice on the other is especially annoying when regarding the mission of educational research. When referring to the classic dualism of 'basic' and 'applied' research, education is a discipline which is typically aiming at both, as for example recently stated in the NRC report "Scientific 
Research in Education" (2002). Thus, what is at stake here is what Stokes (1997) labelled "research in Pasteur's quadrant": Doing research which is at once contributing to the resolution of concrete problems on the one hand, and contributing to theory-building by improving the understanding of educational problems on the other.

Following recent discussions in educational science, one gets confronted with the idea that part of the failure to influence practice might in fact be a failure to produce scientific results that can be generalized; in other words: a failure to do sound basic research. In order to influence practice, enhancing the explanatory and predictive power is seen as a crucial prerequisite. Thus, the current debate is in part about what educational research should be like from a methodological point of view in order to be meaningful. The question of how this is to be achieved is subject to an ongoing, fruitful controversy (see e.g. Phillips 2006 for an overview of the state of the debate). One strand of research tries to achieve a maximal range of applicability by conducting randomized, large scale trials. The underlying assumption with regard to practical relevance is that by doing research on such a broad empirical basis, all possible real-world context factors will be addressed with the consequence that research results must almost necessarily be robust across a wide range of implementations. This applies, for instance, to all approaches summarized under the label 'Scaling up' (e.g. MacDonald et al. 2006). The counter position holds that due to the highly contextual nature of educational phenomena, research should cease to strive for maximal generalization and look for practically relevant results in in-depth case-based studies (e.g., Arnseth \& Ludvigsen, 2006). Still others argue that educational phenomena can only be properly addressed by appropriate mixes of different methodical approaches, for instance via combining lab and field research (Mandl \& Stark, 2001). Whatever the case, it is interesting to note that most of these approaches promote their preferred research design as the best way to generate practically useful results. 
Closely interwoven with these rather epistemological questions of how powerful scientific claims can be in dependence of the way they were generated is the aspect of persuasiveness of educational research. The esteem of the underlying methodology can have an impact on whether scientific claims are rejected or accepted by other societal actors such as policy makers or educational practitioners. Therefore, a concern for methodical questions is not only related to the nature and scope of knowledge, but also to the public image and trustworthiness of a science branch, and this is neither a new phenomenon in educational research (Kennedy, 1997) nor probably in any other discipline. Thus, methodological decisions must not only be regarded as a way of generating practically useful research results, but also of generating the authority needed for the uptake by practice.

Thus, sound research is relevant for good educational practice in several respects. However, it cannot be supposed to be sufficient. Corroborating the basis is one thing, communicating and transferring the contents another. In the following, we will turn to the interface between the realms of research and practice. To explore what might (ideally) happen there, we tried to establish an inventory of existing ideas about interaction between research and practice. One problem one encounters in doing so is that theories about "how to get things across" stem from very diverse contexts. The 'diffusion of innovations' (to cite the title of the influential book by Rogers, 1995) and the management of knowledge is as vital as a business and organizational science issue as it is interesting from a cognitive psychology or communication theory viewpoint. Not to mention those approaches that directly target what they call 'science transfer'. And, after all, the processes playing a role here can also be regarded as some sort of 'learning'. We tried to cope with this diversity by peeling off the discipline-specific conceptual frameworks in order to reduce them to a core idea. To describe, summarize, and compare these core ideas within a common framework we chose to refer to a concept widely used in the disciplines of education science, psychology and computer science, namely the notion of 'scripts'. We thus used a scripting terminology including 
concepts like goals, roles, activities as a structuring heuristic to analyse, describe, and compare various models of establishing relationships between the two realms and their possible use in the researcher's toolkit when engaging with practice.

The scripting perspective

The term "script" is rooted in cognitive psychology (Schank \& Abelson 1977) and refers to procedural knowledge specifying the typical sequence of actions in a recurring type of events. A script can thus be regarded as a kind of blueprint for a series of actions; its status is that of a plan of what should typically happen. Therefore, it mustn't be confused with the actual pattern of actions which might in fact differ from the script.

One specifically interesting group of scripts, namely collaboration scripts, is addressing the interaction in social situations. Here, a script is in the first place a representation of interaction processes located in the participating persons' minds. An oftencited example for a script is the sequence of activities related to going to a restaurant, that is: entering, finding a seat, ordering a meal, etc. Scripts can greatly reduce coordinative effort between interacting partners - for instance, in the example of the restaurant script, between the customer and the waiter. However, this presupposes that the partners have compatible scripts in mind, which may for instance not be the case if they have a different cultural background. To make sure all participants follow the same script, behaviour can alternatively also be 'scripted' via externally represented roles and prompts as in a screenplay. Educational interventions use these kinds of explicit scripting to trigger learning activities that people typically would not engage in if left on their own (cf., for instance, O’Donnell \& Dansereau 1992; F. Fischer, Kollar, Mandl \& Haake, 2007). In instructional research, scripts can also be seen as a specific kind of scaffolding, namely scaffolding of sequences of collaborative activities (e.g., Kollar et al., 2006). 
Thus, collaboration scripts can be double-faced in two respects. They can be used to describe collaborative activities, but they can also have prescriptive power; they can (as a mental representation) reside 'inside the head' of the participating individuals and/or be 'externally' implemented in the environment in which the interaction takes place.

Regardless whether scripts are externally or internally represented, there are certain constitutive elements which define the script (Kollar, F. Fischer, \& Hesse 2006): (1) the objective of the interaction, for instance: learning; (2) the type of activities (with varying levels of specification; to stay with the learning example, this might be summarizing, questioning, explaining and the like); (3),the sequencing of these activities, (4) the distribution of roles among the interacting partners (as, for example, 'explainer' and 'commentator'), and (5) how the script is represented (e.g. mentally, textually, modelled or otherwise supported by a facilitator, as an affordance of the interaction environment, etc.). For our purpose, this means that the scripting perspective addresses some issues which are not explicitly dealt with by other approaches: It explicitly includes talking about roles for individuals, and it allows for taking into consideration a whole series of interactions instead of a single communicational turn.

Leaving the question of how the script is represented aside for a while, we try in the following to describe various suggestions of what should happen at the research-practice interface in terms of certain roles and actions to be performed by both actors respectively, that is: in terms of a script. Most of these roles and actions can best be described when imaging the overall sequencing into which these activities are embedded as a production chain of knowledge, that is: a sequence of defining the problem, designing and conducting research, analysing data, and disseminating and adopting results. While it is clear that this sequence is grossly simplified in its straightness and reveals nothing of the multiple drawbacks, loops and overlaps of the reality of research processes, it is still useful as a structuring framework - and 
moreover, it seems to be the underlying idea of many of the scripts described in the following. For instance, a defining aspect of these scripts is, among others, at which of these stages of research they target primarily. A further distinguishing feature of the presented scripts is inherent in the role concept, but should be mentioned here explicitly: Just as in everyday life, different roles imply interactions of differing frequency, duration and intensity, from the mere handover to long phases of continued, orchestrated collaboration. And finally, the scripts differ in as to whom they ascribe roles of making an input and taking initiatives. In the following description, the scripts are grouped according to this rationale into unidirectional scripts (science input), loop scripts (practice input) and highly interactional scripts (joint input).

The unidirectional script: science 'transfer' to practice

The unidirectional script typically locates the initial impulse for transferring knowledge within science itself. The basic assumption on which the following approaches build is that research has something - that is, scientific knowledge - which practice is lacking; hence the respective 'product' has to be transferred in order to achieve practice improvement. Research and practice thus assume the roles of sender and receiver, respectively (see figure 1 and the resume in table1).

This conception draws from the same source as many classic models of science popularization (Gregory \& Miller, 1998), that is the assumption of a pronounced knowledge asymmetry between scientific experts and laypersons (with practitioners being conceived as the latter ) - which, of course, implies that science holds a monopoly of judging what is right or wrong (Hilgartner, 1990). Its unidirectional, “pipeline”-like outline (Greeno, 1998) fits well into the larger "linear model" identified by Stokes (1997) which posits a knowledge flow from basic research to applied research to development and, finally, to use. As Stokes points out, this approach is what is largely understood under "research transfer". 


\section{Addressing accessibility}

The unidirectional sender-receiver script is a theme with variations. One way to address the problem of knowledge transfer between research and practice follows the spatial metaphor of "getting things across" quite literally. This strategy relies on making research results physically accessible to the target group: Put your research where practice can find it. In his framework of knowledge transfer "boundaries", Carlile (2004) categorizes actions of this sort as transgressions of the "syntactic boundary" as they are essentially a matter of positioning. This could mean, for instance, to publish in journals that practitioners will probably read, to attend conferences that practitioners also go to, and the like. Another measure that follows pretty much the same logic is to create one-point-accesses to certain fields of research, for example via databases or internet portals. Thus, in the field of education, the creation of the ERIC data base can be counted as an early example (Peterson \& Emrick, 1983). All in all, the essence of this strategy is about storage and retrieval. It is a fundamentally resource-oriented approach which has not only prospered in the 1960ies and 70ies (see, for instance Havelock, 1973), but has lived a renaissance around the millennium due to the revolutionary development of digital media. In fact, much of the literature dealing with knowledge management (for instance: Davenport \& Prusak 1998) can also be applied to the problem in this way (see table 2).

\section{Addressing comprehensibility}

The ease of access is a critical feature for the issue of knowledge transfer, but it is critical in a twofold sense. The research transfer activities described up to now target only what could be described as the physical accessibility of research results to the practitioner. However, another precondition for successful research transfer is the intellectual accessibility, i.e. comprehensibility of research. As Carlile (2004) points out, a "common lexicon" is essential for knowledge transfer to happen. All relevant notions must be shared, or in other 
words, all participants must share a language to a certain extent. The meeting of science and practice is the classic case where this does usually not apply. To stay with Carlile's (2004) terminology, there is a "semantic boundary" that has to be surmounted in addition to the "syntactic" one. This is where all kinds of 'translation efforts' come into play (cf. table 2). In particular, there is a substantial body of research on expert-layperson communication that applies to this issue. The challenge is mostly seen on the side of the communicating expert who has to engage in appropriate "audience design" in order to get his or her ideas across (see table 2). Psycholinguistic research has contributed many insights on the details of these efforts to adapt the message to the knowledge level of the partner. The ideas of Clark (Clark, 1996, Clark \& Murphy, 1982) on how a speaker uses certain hints to make inferences on his or her knowledge have proven to be particular inspiring, also from a practical point of view. For instance, Bromme, Jucks \& Wagner (2005) could show in a health counselling context how medical experts adjust the content and wording of their advice to the technicality of fictitious patient inquiries.

Taken together, both the accessibility and the comprehensibility enhancement activities at the research-practice interface basically refer to early models of communication theory in the tradition of Shannon and Weaver (1949), as the educational researcher Michael Huberman (1983) points out. This is both a strength and limitation: On the one hand, this type of script can rely on a large body of theory and experience in the realm of communication which can be fruitfully applied to the problem at hand. On the other hand, it has some blind spots as well. One important drawback is that this script tacitly presumes that practice is committed and readily assumes its role as a receiver, i.e. that practitioners actually read the scientists' publications within their reach. However, it seems to be a matter of fact that they simply don’t (Burkhardt \& Schoenfeld 2003; Landry, Amara, \& Lamari 2001). Furthermore, important aspects which happen not to be related to issues of transmission or presentation are not addressed. One such aspect is the question of relevance. If practitioners regard research as 
irrelevant for the problems they are facing in everyday professional practice, they will make no use of it regardless of how easily accessible and nicely explained it might be. Relevance is something more fundamental, determined by the phenomena and questions addressed by research. It is thus something which cannot be 'added' to a research endeavour after its completion, but must be considered right from the start. In other words: The business of research transfer might start with the choice of the issue to be investigated and thus at the very beginning of a knowledge production cycle. The script presented in the following section takes heed of this fact.

The loop script: From practice to science and back

The most prominent characteristic of the script presented now is that it conceptualizes the information flow between research and practice not as a straight line, but as a loop. The principal difference with regard to the unidirectional script presented earlier is that the question to be investigated scientifically is not (or at least not solely, as will be specified later) generated by scientists alone. Whereas much research is almost exclusively inspired by the scientific state-of-the-art and the literature that reports it, this script advises that one should draw the problem from the realm of practice instead (see figure 2 and the resume in table 3 ). Landry, Amara and Lamari (2001) therefore label this type of approach as a "demand pull model" in contrast to the "science push model". The assumption is that, under these conditions, whatever result scientific research can feed back to practice will almost necessarily meet the practitioners' needs.

The basic model of this script primarily envisages activities at the research-practice interface at the beginning (problem definition) and the end (dissemination) of the production chain of knowledge. Thus, the 'inner' processes of research need not be affected by practitioner interference. In principle, research can work as a black box, the role distribution between research and practice being that of service provider and customer: Hand over your 
problem, and we'll do the rest. Thus, there is interaction between the two realms, but not a highly interactive one; which might not be enough to overcome mutual prejudices where they are deeply entrenched (Huberman, 1990).

Extending the loop script towards a closer collaboration: Use-inspired basic research

While the basic loop script ensures the practical relevance of scientific research, another concern is not so easily addressed: the twofold mission of research formulated at the beginning of this article, which is the simultaneous advancement of understanding, i.e., theory-building, and use in practice. While the problem of significance for the realm of practice seems resolved, this is done at the price of a largely utilitarian view on research. The epistemological goal of building knowledge on how phenomena relate generally might be missed out in the pursuit of a concrete problem solution. Two factors fostering such a development are common: On the one hand, from a scientific perspective, practice problems are only very rarely problems that inspire cutting-edge research, but rather represent 'scientific problems of the past'. From the practical perspective, on the other hand, it is not necessarily interesting to generalize on the basis of a research-based problem solution to a general model or theory.

An approach trying to counteract such tendencies runs under the label of "use-inspired basic research" (Stokes, 1997), which demands a double quality of the research question: It should have a practical as well as a theoretical appeal and thus be located in "Pasteur's quadrant” (Stokes 1997). Stokes underscores that against popular belief theoretical and practical interests needn't be mutually exclusive. Nonetheless, it is obvious that they can diverge. Thus, what has to be worked out is a heuristic to systematically identify research questions which meet both criteria. It doesn't seem plausible that such questions can be successfully generated by either research or practice without interacting with the other side. Probably, they will rather have to be negotiated between the two. 
Thus, for the first time in our description of scripts, this brings to the fore an activity which researchers and practitioners will probably have to carry out jointly. In this respect, the variant "use-inspired basic research" differs from the "research on demand"-version of the loop script: Whereas practice communicates a research need to science in the "research on demand"-version, both parties have to jointly work out this need in the "use-inspired research"-variant (see table 4). The next section presents a script that expands on this idea and slates multiple loops of the knowledge production cycle encompassing multiple joint working phases between science and practice.

\section{Iterative loops and "Design-based Research"}

Basically, the whole process of knowledge generation can be imagined as a cycle which can start anew on the basis of the feedback which is generated by the practical use of its results. In case of unexpected effects of application (whether they may be positive or negative) the issue can be re-submitted to scientific investigation, thus allowing for continuous refinement.

This idea of iterated cycles of research and practical implementation is what is commonly regarded as the core mechanism of engineering and has been taken up by a strand of educational research labelled design research (Brown, 1992; The Design-Based Research Collective, 2003). In order to achieve research results clearly relevant to the needs of practice, it advocates multiple loops of design, enactment, analysis, and redesign. The core argument put forward for the inclusion of the 'enactment' stage (instead of any other empirical approach) into the realm of research is that due to the context dependency and uniqueness of educational phenomena, valid testing can only be done in practical case studies (in contrast to lab research, for instance) (The Design-Based Research Collective, 2003). However, what is blurred in this approach is the role distribution between researcher and practitioner. The design-based research orientation opts for a close collaboration of researchers and 
practitioners in which no clear task assignment is discernible. Rather, field research seems to merge into actually 'designing' practice. In this respect, 'design-based research' already belongs to a last group of scripts, which are characterized by a high intensity of interaction between research and practice.

\section{Highly interactive scripts}

In the emphasis put on the close collaboration between research and practice, the 'design-based research' approach responds to the widespread demand for a more 'dialogical' communication and participatory structures (Burns et al. 2003) in the relationship between research and practice. However, this demand is not very clearly formulated with regard to the concrete activities happening at the research-practice interface. Here, pioneering conceptual work still needs to be done, and a scripting perspective can provide some useful notions for building an overarching framework. In order to describe such highly interactional scripts further, the aspects to be addressed are the frequency and the intensity of interaction.

What clearly differentiates 'interactional' modes of knowledge production (Landry, Amara, \& Lamari 2001) from the "unidirectional" and the "loop" scripts is that contacts between the realms of research and practice are not limited to the stages of 'before' and/or 'after' research. Instead, a continuous involvement of practitioners during research is regarded as essential. Research encompasses a number of activities (problem definition, research design, research conduct, data analysis, and the dissemination of results, cf. table 5) which we have postulated above as a sequential framework ("the production chain of knowledge") and which could, at least in principle, all be executed on the basis of an interaction between research and practice. Here and there, some ideas for which kind of interaction should mark each stage are already discernible. The idea of finding a research question in "Pasteur's quadrant" described when dealing with the "use-inspired research"-script, for instance, could work as a sub-goal for interaction in the stage of problem definition - a goal which would 
have the positive side-effect of making mutual benefits more likely. As to the stage of designing and conducting research, there are some approaches in educational research which plead for a joint execution of field research, for instance Stark's and Mandl's “integrative research paradigm" (2001; this issue) or the Design-based Research Collective (2003). For the stage of data analysis, there are studies that indicate that a joint interpretation of the data can have a positive effect on the usefulness of research as perceived by practitioners (Albers Mohrman, Gibson, Mohrman, 2001). Finally, the problem of disseminating research results among the targeted practitioner community - a problem that forms the starting point of reflections in the unidirectional approaches - is almost resolved in passing in the interactional script variants. Huberman (1983) describes this as his "linkage thesis": The more frequent, reciprocal, and continuous the exchanges between research and practice, the greater the interdependence and, in turn, the greater the impact within the realm of practice (see also Huberman, 1990 for empirical evidence). The assumption that dissemination is rather something achieved throughout the process due to its participatory character instead of something neatly separated from the craft of knowledge generation is very typical for this type of script. It therefore shows parallels to the "mode 2" of knowledge production as described by Gibbons et al. (1994) in which research and practice co-evolve. Keeping the large body of research on the spread of innovations in mind, we may assume that this type of dissemination has great chances of success: Much more than the other approaches outlined in this article, it takes heed of the fundamental fact that ideas travel by people (Czarniawska, 1996). More precisely, they travel easiest from peer to peer (Rogers, 1995; Ryan \& Gross, 1943). Individuals who spread new insights gained elsewhere within their home unit are usually much more successful than external change agents (Gruenfeld, Martorena, \& Fan, 2000). By engaging practitioners in the process of research, the boundary between the two realms has already been crossed long before the stage of dissemination is reached. At that point, it gets clear that our initial image of knowledge production as a chain of sharply 
separated sequential processes does not hold any longer and has to be abandoned. In a highly interactive script, especially the phases of doing research and the dissemination of results might in fact merge.

What could help to categorize "interactional" approaches as to the closeness of interaction is defining whether the researcher-practitioner interaction is rather cooperative or collaborative. Research on learning in groups sometimes refers to this differentiation (Roschelle \& Teasley, 1995) and basically defines continuous joint efforts as collaborative whereas cooperative learning and working relies on a distribution of tasks among the partners. Accordingly, collaborative research would mean an even closer interaction between researchers and practitioners than cooperative endeavours. In other words: the cooperative variant would amount to the "dialogical" structure requested by proponents of a closer relationship between science and its environment, whereas collaboration would mean participatory research endeavours.

Consequently, role definitions would differ: Whereas cooperation is based on the idea of complementary expertise and/or responsibilities, collaborative interaction rather implies the idea of a community of members with equal rights, duties and abilities. Each variant could draw upon a rich body of research on collaboration in teams with complementary expertise (Rummel \& Spada, 2005) and on community practices and culture (Ellis, Oldridge, \& Vasconcelos, 2004), respectively. Note that in contrast especially to the unidirectional scripts, the idea of the knowledge deficit in the realm of practice is abandoned in both variants of the interactional scripts. Instead, both sides are regarded as having the ability to bring in something useful, which opens up the possibility to reap mutual benefits from the cooperation (or collaboration, respectively). Research on cooperation and collaboration - be it in the field of education or elsewhere - emphasizes the importance of the mutual benefits precondition for the success and sustainability of the joint endeavour (Slavin 1995, Bielaczyc \& Collins 
1999, Kollock 1998). However, it has to be taken into account that highly interactional scripts are also highly demanding in terms of time and effort, which leads us to our concluding reflections (see table 5).

\section{Conclusions}

After presenting a variety of approaches to resolve a problem, it is always tempting to argue that one of these alternatives is actually 'the right one' and to explain why. We would like to modify the question and ask which alternative might be the right one under which conditions.

The scripts we have described above have a rather dissimilar focus. Most approaches (with the possible exception of the interactional scripts) do not address all stages of what we have called "the production chain of knowledge" with the same level of attention. For instance, some emphasize the definition of the research question (as do loop scripts), while others concentrate on issues of communicating and disseminating research contents (unidirectional scripts). Respectively, each of the scripts described above also has certain blind spots: Aspects of the relationship of research and practice which are not addressed by the script and in which ideal starting conditions are tacitly taken for granted. The unidirectional script focuses on the use of communication channels. While its approach of transferring research results to practice may be appropriate in cases where practitioners are not only keenly interested in these results, but also able to understand them, further effort might be required in cases where these conditions do not apply. Doing research which deliberately responds to a well-defined need of practice (the loop script) and the 'translation' of these results can make up for problems of this kind. But it might still not be enough in cases where the successful application of research results to practical problems is highly dependent upon context factors which may vary greatly, as it is typical for educational settings. In such cases, iterative loops of research and implementation are necessary to find 
satisfactory solutions. However, carrying out these repeated cycles of researching and applying with a clear task division between scientists and practitioners may overlook the possibility of a certain 'duality of cultures' of science and practice respectively. Such differences may go well beyond distinct 'languages' and can include quite dissimilar goals and values. If this is the case, only close collaboration and continued personal interaction as scheduled in the highly interactive scripts may lay the groundwork for the desired outcomes although at the price of a considerably high effort on both sides.

To find out which kind and complexity of activities at the research-practice interface is appropriate in which type of case remains an important task for future research. The intention of this article was to present existing ways of how to think about the problem within a single framework, the scripting perspective. Due to the faculty of the scripting viewpoint to address whole series of interaction instead of single communicational turns, this approach leads to a quite holistic, integrated picture. Possibly, the perspective taken here will even provide a heuristic for discovering new areas and ways in which research and practice can relate to one another - or to put it differently, for generating new scripts. The scripting perspective incites to raise the question 'who does what in which sequence', and such thinking about roles, initiative taking, and the process dimension of a relationship can help to colour the white spots in the picture by developing cooperative (or collaborative) schemata in areas that have been left unattended up to now. Although not in the focus of this article it could be worthwhile considering the scripting framework as guidance for the design of self-generated scripts in newly established relationships of scientists and practitioners.

The heuristic value of the scripting perspective can also be applied to issue of scaffolding which is tightly connected to the scripting notion. As outlined above, the scripting perspective does not only provide a comprehensive framework for description, but can also have prescriptive qualities. In fact, this happens to be the dominant use of scripts in the field 
of education: To provide explicit guidance adapted to the demands of the situation and to make people engage in behaviour which they most probably would not have shown otherwise. We thus get back to a defining aspect of scripts according to Kollar et al. (2006) neglected up to now, which is the way a script is represented. Explicit, externally represented scripts may be especially important if no appropriate internal - that is, mental - representations of what a successful researcher-practitioner interaction could look like exist, or if these scripts vary too broadly among the participating researchers and practitioners. To design such explicit scripts that could scaffold interaction at the research-practice interface is a further important task for future research. Existing work on the interplay between internal and external scripts (Carmien, Kollar, G. Fischer, and F. Fischer 2007) may be taken as a starting point. Additionally, an analysis of existing 'scripts' for researcher-practitioner interactions externally implemented for instance in the policies of funding agencies or scientific journals may be revealing.

\section{References}

Arnseth, H.C. \& S. Ludvigsen (2006). Approaching institutional contexts: Systemic versus dialogical research in CSCL. International Journal of Computer-Supported Collaborative Learning. 1 (2), 167-185.

Bielaczyc, K., \& Collins, A. (1999). Learning communities in classroom: A reconceptualization of educational practice. In C. M. Reigeluth (Ed.) Instructional design theories and models. Vol. II: A new paradigm of instructional theory (pp. $286-$ 290). Mahwah, NJ: Erlbaum.

Bromme, R., Jucks, R., \& Wagner, T. (2005). How to refer to 'diabetes'? Language in online health advice. Applied Cognitive Psychology, 19, 569-586. 
Brown, A.L. (1992). Design experiments: theoretical and methodological challenges in creating complex interventions in classroom settings. The Journal of the Learning Sciences, 2 (2), 141-178.

Burkhardt, H. \&, Schoenfeld, A. (2003). Improving Educational Research: Toward a More Useful, More Influential, and Better-Funded Enterprise. Educational Researcher 32, 9, 3-14.

Burns, T.W., O’Connor, D.J., Stocklmayer, S.M. (2003). Science Communication. A contemporary definition. Public Understanding of Science 12(2), 183-202.

Carlile, P. R. (2004). Transferring, Translating, and Transforming: An Integrative Framework for Managing Knowledge Across Boundaries. Organization Science 15 (5), 555-568.

Carmien, S., Kollar, I., Fischer, G., Fischer, F. (2007). The interplay of internal and external scripts. In Fischer, F., Kollar, I. Mandl, H. \& Haake, J.M. (Eds.) Scripting ComputerSupported Collaborative Learning. New York: Springer

Clark, H. H. \& Murphy, G. L. (1982). Audience design in meaning and reference. In J.-F. le Ny \& W. Kintsch (Eds.). Language and comprehension (pp. 287-300). Amsterdam: North-Holland Publishing Company.

Clark, H. H. (1996). Using language. Cambridge: Cambridge University Press

Czarniawska, B., \& Joerges, B. (1996). Travels of Ideas. In B. Czarniawska\& G. Sevón (Eds.) Translating Organizational Change (pp. 13-48). Berlin: Walter de Gruyter

Davenport, T. H., Prusak, L. (1998). Working Knowledge: How Organizations Manage What They Know. Cambridge, MA: Harvard Business School Press.

Ellis, D., Oldridge, R., \& Vasconcelos, A. (2004). Community and virtual community. Annual Review of Information Science and Technology, 38 (1), 145-186. 
Fischer, F., Kollar, I. Mandl, H. \& Haake, J.M.(2007). Perspectives on collaboration scripts. In Fischer, F., Kollar, I. Mandl, H. \& Haake, J.M, Scripting Computer-Supported Collaborative Learning (pp. 1-10). New York: Springer.

Gibbons, M., Limoges, C., Nowotny, H., Schwartzman, S., Scott, P., \& Trow, M. (1994). The New Production of Knowledge. The Dynamics of Science and Research in Contemporary Societies. London: Sage.

Greeno, J.G. \& the Middle School Mathematics Through Applications Project Group (1998). The situativity of knowing, learning and research. American Psychologist, 53(1), 5-26.

Gregory, J, Miller, S. (1998). Science in Public. Communication, Culture, and Credibility. New York: Plenum.

Gruenfeld, M., \& Fan, E.T. (2000). What do groups learn from their worldliest members? Direct and indirect influence in dynamic teams. Organizational Behavior and Human Decision Processes, 82(1), 45-59.

Hargreaves, D. (1999). The knowledge-creating school. British Journal of Educational Studies, 47(2), 122-144.

Havelock, R.G. (1973). The change agent's guide to innovation in education. Englewood Cliffs, N. J.: Educational Technology Publications..

Hilgartner, S. (1990). The Dominant View of Popularization: Conceptual Problems, Political Uses. In Social Studies of Science 20, 519-539.

Huberman, A.M. (1983). Improving social practice through the utilization of university-based knowledge. Higher Education, 12, 257-272.

Huberman, M. (1990). Linkage between Researchers and Practitioners: A Qualitative Study. American Educational Research Journal, 27 (2), 363-391. 
Kennedy, M. M. (1997). The Connection between Research and Practice. Educational Researcher, 26 (7), 4-12.

Kollar, I., Fischer, F., \& Hesse, F.W. (2006). Collaboration Scripts - A Conceptual Analysis. Educational Psychology Review, 18 (2), 159-185.

Kollock, P. (1998). Social dilemmas: The Anatomy of Cooperation. Annual Review of Sociology, 24, 183-214.

Landry, R., Amara, N., Lamari, M. (2001). Utilization of social science research knowledge in Canada. Research Policy, 30, 333-349.

Logan, R.A. (2001). Science Mass Communication. Its Conceptual History. Science Communication 23(2), 135-163.

Mandl, H., \& Stark, R. (2001, April). Pasteur's Quadrant in Educational Psychology: Useinspired basic research to overcome the gap between theory and practice. Paper presented at the AERA Annual Meeting, Washington.

McDonald, S.K., Keesler, V., Kauffman, N.J., Schneider, B. (2006). Scaling-up Exemplary Interventions. Educational Researcher, 35(3), 15-24.

Mohrmann, S.A., Gibson, C.B., \& Mohrmann, A.M. (2001). Doing research that is useful for practice: a model and empirical exploration. Academy of Management Journal, 44, 357-375.

Nonaka, I., \& Takeuchi, H. (1995). The knowledge-creating company: How Japanese Companies create the Dynamics of Innovation. Oxford: Oxford University Press.

O’Donnell, A., \& Dansereau, D.F. (1992). Scripted Cooperation in Student Dyads: A Method for Analyzing and Enhancing Academic Learning and Performance. In R.HertzLazarowitz \& N. Miller (Eds.), Interaction in cooperative groups. The theoretical anatomy of group learning (pp. 120-141). Cambridge: Cambridge University Press. 
Pea, R.D. (2004). The social and technological dimensions of scaffolding and related theoretical concepts for learning, education, and human activity. Journal of the Learning Sciences, 13 (3), 423-451.

Peterson, S. M., Emrick, J. A.. (1983). Advances in Practice. In W. J. Paisley and M. Butler (Eds.): Knowledge utilization systems in Education. Dissemination, Technical Assistance, Networking. London: Sage.

Phillips, D.C. (2006). A guide for the perplexed: Scientific educational research, methodolatry, and the gold versus platinum standards. Educational Research Review, $15-26$.

Rogers, E. M. (1995). The Diffusion of Innovations. New York: The Free Press.

Roschelle, J., \& Teasley, S. (1995). The construction of shared knowledge in collaborative problem solving. In C. E. O'Malley, (Ed.), Computer-Supported Collaborative Learning (69-97). Heidelberg: Springer-Verlag.

Rummel, N. \& Spada, H. (2005). Learning to collaborate: An instructional approach to promoting collaborative problem-solving in computer-mediated settings. Journal of the Learning Sciences, 14(2), 201-241.

Ryan, B. \& Gross, N.C. (1943). The Diffusion of Hybrid Seed Corn in Two Iowa Communities. Rural Sociology, 8 (May), 15-34.

Schank, R.C., \& Abelson, R.P. (1977). Scripts, plans, goals and understanding. Hillsdale, NJ: Erlbaum.

Shannon, C., \& Weaver, W. (1949). The Mathematical Theory of Communication. Urbana, IL: University of Illinois Press.

Shavelson, R.J. \& Towne, L. (Eds.) (2002). Scientific Research in Education.Washington, DC: National Academies Press. 
Slavin, R. E. (1995). Cooperative learning: Theory, research, and practice (2nd ed.). Boston: Allyn \& Bacon.

Stokes, D.E. (1997). Pasteur's Quadrant: Basic Science and Technological Innovation. Washington, D.C.: Brookings Institution Press.

The Design-based Research Collective (DBRC) (2003). Design-based research: An emerging paradigm for educational inquiry. Educational Researcher, 32 (1), 5-8. 
Author Note

Korinna Bauer, Helmholtz Association of German Research Centres, and Frank Fischer, University of Munich

The authors are grateful to Thomas Eckert for commenting an earlier version of this manuscript.

Correspondence concerning this article should be addressed to Frank Fischer, Leopoldstr. 13, D-80803 Munich, Germany. Telephone: +49 89 2180-5146, Fax: +49 89 2180-16540, Email: frank.fischer@psy.lmu.de 
Table 1

Unidirectional script 1: Science transfer

Objective: Improving practice - as a by-product of building scientific knowledge

Activities: Conducting research and transferring its results to places where practitioners can pick it up

Sequence: (1) Research is conducted, (2) results are transferred/ communicated, (3) results are retrieved and adopted

Role distribution: scientists act as producers and senders; practitioners act as receivers and adopters 
Table 2

Unidirectional script 2: Transferring 'translated' science

Objective: Improving practice - as a by-product of building scientific knowledge

Activities: Conducting research, translating its results into a language comprehensible for a practitioner audience, and transferring its results to places where practitioners can pick it up Sequence: (1) research is conducted, (2) results are translated (3) results are transferred/ communicated, (4) results are retrieved and adopted Role distribution: scientists act as producers, translators and senders; practitioners act as receivers and adopters 
Table 3

Loop script 1: Research on demand

Objective: Improving practice

Activities: Articulating a research need perceived by practice, conducting research, transferring its results to places where practitioners can pick it up

Sequence: (1) a practically relevant research question is formulated, (2) research is conducted, (3) results are transferred/ communicated, (4) results are adopted Role distribution: Practice acts as customer who articulates needs; science acts as a service provider 
Table 4

Loop script 2: Use-inspired basic research

Objective: Improving practice and building scientific theory

Activities: Defining a research need perceived by practice that enables cutting edge basic research, conducting research, transferring its results to places where other scientists and practitioners can retrieve it

Sequence: (1) a scientifically and practically relevant research question is formulated, (2) research is conducted, (3) results are transferred/ communicated, (4) results are adopted Role distribution: science and practice collaborate in defining a research need, science conducts research, science transfers the results to practice, practice adopts the results 
Table 5

Highly interactive scripts

Objective: Improving practice and building scientific theory

Activities: problem definition, research design, research conduct, data analysis, dissemination of results, adoption, re-definition of the problem, etc.

Sequence: stages of the knowledge production sequence can merge

Role distribution: science and practice collaborate or cooperate at multiple stages of the process; practitioners may act as researchers, scientists may act as designers of educational environments 


\section{Figure Caption}

Figure 1. Research and practice assume the roles of sender and receiver

Figure 2. Research draws its inspiration from practice and feeds the results back. 

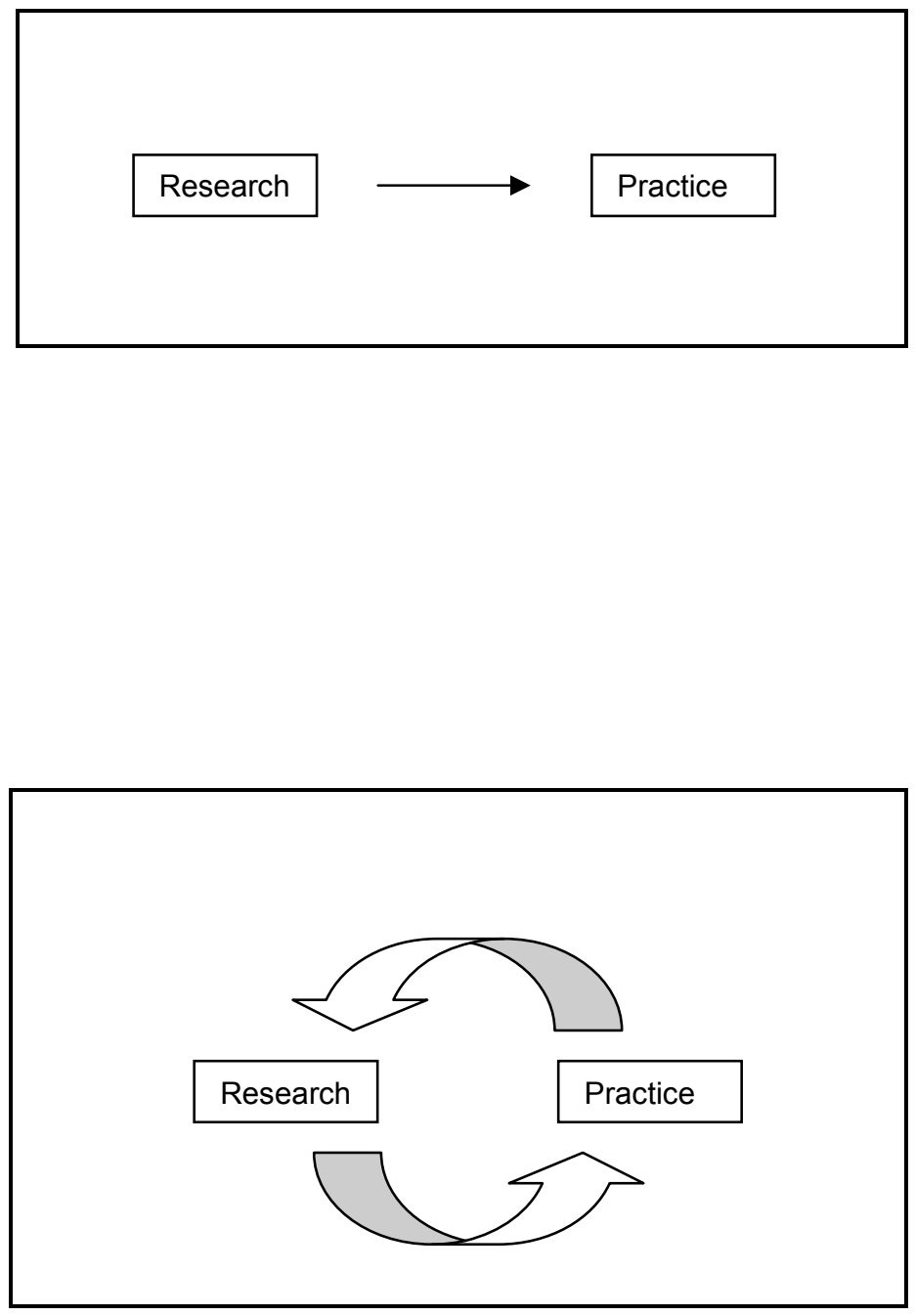
